\title{
Produções acadêmicas em Libras como ferramentas de política linguística das comunidades surdas brasileiras
}

Rodrigo Custódio da Silva ${ }^{1}$

\section{Resumo}

Este trabalho apresenta propostas de producões acadêmicas em Lingua Brasileira de Sinais (Libras) e busca discuti-las enquanto ferramentas de politica linguistica das comunidades acadêmicas surdas do Brasil. Para contextualizar o tema, algumas consideracõos acerca da bistória da lingua de sinais no Brasil são apresentadas, bem como reflexões sobre sua difusão, o uso de novas redes de comunicação e os contextos educacionais e acadêmicos de uso da Libras. Referências teóricas e legais, acerca da língua de sinais na interface acadêmica e seu respectivo registro formal, são trazidas para embasar este trabalho. Este artigo implica num repensar atento sobre a importância de um maior investimento na produção de mais materiais que abranjam novos gêneros de uso e registro da língua de sinais no Brasil, uma vez que são importantes vias de solidificação da lingua e comunidades surdas e funcionam como significativas ferramentas de política linguística.

Palavras-chaves: Libras. Produções acadêmicas. Politicas linguísticas

\footnotetext{
${ }^{1}$ Mestre em Linguística pela Universidade Federal de Santa Catarina e doutorando em Linguística pela mesma instituição. Professor do curso de Letras-Libras da UFSC.
}

Revista Leitura v. 1, no 58 - Maceió - Jan./Jun. 2017 - ISSN 2317-9945

Línguas de Sinais: abordagens teóricas e aplicadas, p. 107-123 


\section{Introdução}

O presente trabalho foi construído partindo da seguinte questão central: existem propostas, disponibilizadas na internet ${ }^{2}$, que sustentam as políticas linguísticas das comunidades acadêmicas Surdas no Brasil? Na busca de uma possível resposta para essa questão, objetiva-se realizar um levantamento de algumas iniciativas pertinentes a respeito das políticas linguísticas associadas à Língua Brasileira de Sinais (Libras) e, em especial, às comunidades acadêmicas surdas no seu uso e registro formal e acadêmico. Propõe-se com as reflexões apresentadas neste trabalho contribuir com a construção de novos olhares para as possibilidades e expectativas a cerca das produções acadêmicas em Libras e suas normas. Normas que, por sua vez, passam a ser pensadas e aplicadas no campo acadêmico e a partir de uma perspectiva de consolidação e reconhecimento linguístico, funcionam, portanto, como ferramentas de política linguística.

Percebe-se que o registro formal e as produções acadêmicas difundidas diretamente em língua de sinais no Brasil ainda encontram-se incipientes. Em seu modo de registro acadêmico, em muitos casos, a Libras ainda enfrenta limitações quanto à importância de seu uso, reconhecimento e consolidação. Essas limitações estão presentes nas diferentes esferas do ensino, inclusive, na esfera universitária. Um desses fatos é a carência dos materiais didáticos que compreendam a questão de gêneros textuais acadêmicos produzidos diretamente em língua de sinais.

Segundo Machado, Lousada e Abreu-Tardelli (2005, p. 13), "Frequentemente, os alunos são cobrados por aquilo que nunca lhes é ensinado, tendo de aprender por conta própria, intuitivamente, com muito esforço". As autoras observam as dificuldades de produções textuais nos diferentes contextos de educação (níveis escolares e acadêmicos) em geral. Por outro lado, as comunidades acadêmicas surdas no Brasil passaram a ser destacadas nos últimos anos e, ainda continuam crescendo. Mesmo assim, é possível perceber que acabam enfrentando algumas dificuldades para organizar e produzir gêneros textuais acadêmicos. Essa dificuldade pode estar ligada à carência de materiais didáticos específicos em Libras.

Embora sejam iniciativas que estejam crescendo, pode-se lembrar que são poucas as instituições de ensino superior que atualmente viabilizam provas de vestibulares e

\footnotetext{
${ }^{2}$ Os meios disponibilizados na internet são mais fáceis tanto de explorar como de serem compartilhados no nosso conhecimento.
} 
concursos diretamente em língua de sinais, ou seja, na primeira língua (L1) de seus candidatos surdos. O que se percebe é ainda uma política majoritária do uso da língua portuguesa - segunda língua dos surdos usuários da Libras - nas provas de processos seletivos e outros tipos de provas. Um exemplo disso é o Exame Nacional do Ensino Médio, o ENEM.

Apesar de as políticas linguísticas passarem a reconhecer cada vez mais a Libras como primeira língua (L1) dos surdos brasileiros, ainda é possível perceber um despreparo e/ou falta de conhecimento dos agentes da educação desses contextos citados em relação à língua de sinais, o que implica reproduções de políticas monolíngues.

Alguns desdobramentos das políticas linguísticas da Libras merecem atenção, como pontos a serem exemplificados neste artigo, de modo a contribuir para perspectivas linguísticas e políticas, envolvendo as possibilidades e do futuro da língua de sinais no cenário brasileiro. Foca-se aqui, portanto, na consolidação de materiais, produções acadêmicas e suas respectivas normas textuais acadêmicas em Libras, justamente como ferramenta política, uma vez que a comunidade acadêmica surda, sobretudo os agentes proponentes de muitas das iniciativas dessas vias e ferramentas (surdos acadêmicos), acreditam que discutir sobre uma nova configuração da língua de sinais pode também contribuir significativamente para a sua valorização e difusão.

\section{Percurso histórico e a constituição da Libras no Brasil}

Para melhor compreender o contexto em que o tema deste artigo se apresenta, retoma-se brevemente o percurso da língua de sinais no Brasil e alguns aspectos relevantes sobre a importância da língua de sinais para as comunidades Surdas, bem como quais bases hoje sustentam as políticas linguísticas e seu fortalecimento.

As línguas de sinais são línguas utilizadas pelas comunidades surdas. Elas não são universais, uma vez que cada país tem a sua própria língua sinalizada (GESSER, 2009; QUADROS \& KARNOPP, 2004). Segundo Diniz (2010) e Campello (2011), registros indicam que a origem da Língua Brasileira de Sinais é francesa e, portanto, com influência da Língua de Sinais Francesa (LSF). Diniz (2010) e Campello (2011), assim como inúmeros autores que estudam sobre as origens da língua de sinais no Brasil e seu percurso histórico 
ao longo dos tempos, relatam que parte da história da Libras decorre da vinda de um professor francês ao Brasil. Convidado pelo imperador Dom Pedro II para ministrar aulas para alunos Surdos, Eduard Huet tinha sólida formação e experiência decorrente de cursos ministrados para surdos em Paris, o que muito contribuiu com o sucesso da língua de sinais junto aos seus novos alunos surdos no Brasil.

Outro ponto importante no processo histórico da Libras no Brasil e sua constituição foi a criação da primeira instituição de ensino destinada às pessoas surdas no Brasil, o hoje conhecido Instituto Nacional de Educação de Surdos (INES), localizado no Rio de Janeiro, em funcionamento. Posterior a isso, e a partir da década de 80, a pesquisadora Lucinda Ferreira ${ }^{3}$, autora do livro Por uma Gramática de Linguas de Sinais, passou a estudar a Língua Brasileira de Sinais de forma mais aprofundada e com um olhar linguístico e científico. Por meio de suas pesquisas, difundiu estudos acadêmicos pioneiros que contribuíram muito com as comunidades surdas brasileiras, inspirando muitos outros pesquisadores que vieram depois a aprofundar seus trabalhos e investigações sobre a língua. É válido ressaltar a importância dessas pesquisas, considerando que a ação de pesquisar reflete-se numa transformação de conhecimento social, científico e humano, e ainda contribui efetivamente para o reconhecimento e valorização das línguas, em especial, a Libras. Compartilhando as palavras de Ferreira:

Com a Sociologia e a Antropologia - o papel que desempenham as línguas de sinais nas sociedades ocidentais tem sido secundário, limitando-se o seu uso a pessoas e lugares restritos e sendo elas alvo de preconceitos e desprestígio. As pesquisas linguísticas sobre uma Língua de Sinais revalidam seu status de língua, conferindo-lhe mais prestígio e, portanto, respeito. Isso implica numa reestruturação social no que diz respeito ao espaço que os surdos ocupam na sociedade em que vivem. Revalidando-se a língua, revalida-se também a cultura surda e isto permite ao surdo melhor desempenho da sua função enquanto cidadão (FERREIRA, 2010, p. 13).

Foi após muitos anos de luta por seus direitos linguísticos e respeito às comunidades Surdas que os Surdos brasileiros - junto à Federação Nacional de Educação e Integração de Surdos (Feneis) e demais entidades representativas e militantes engajados com a causa - conquistaram o reconhecimento legal da Língua Brasileira de Sinais como meio oficial de comunicação dos Surdos. Foi por meio da Lei no 10.436 , de 24 de abril de 2002 que a Libras foi reconhecida como forma legítima de comunicação natural dos surdos no Brasil. Cabe pontuar que, na legislação, a Língua Brasileira de Sinais é entendida como

3 Outros livros citam "BRITO, Lucinda Ferreira", mas o presente artigo cita "FERREIRA, Lucinda" devido à ficha catalográfica registrada no livro "Por uma Gramática de Linguas de Sinais" publicado em 2010. 
um meio de comunicação e expressão, cujo sistema linguístico é de natureza visual-motora e possui estrutura gramatical própria. Trata-se de "um sistema linguístico de transmissão de ideias e fatos oriundos de comunidades de pessoas surdas do Brasil” (BRASIL, 2002, p. 23).

Tal lei foi regulamentada pelo Decreto $\mathrm{n}^{\circ}$ 5.626, três anos depois, em 22 de dezembro de 2005. Esse, por sua vez, foi instituído no desígnio de assegurar o direito dos surdos à educação de forma acessível, sendo sua comunicação realizada por meio da mediação de profissionais intérpretes. Legalmente, essa mediação comunicacional prevê a abrangência das instituições públicas de ensino de todos os níveis educacionais, desde o ensino fundamental até o ensino superior.

Por decorrência dessas conquistas legais, considera-se que o número de surdos nos contextos educacionais e acadêmicos, bem como a presença de surdos professores formados e capacitados para atuação no ensino da língua de sinais nessas esferas aumentou consideravelmente. Assim como a própria visibilidade e o respeito da Libras e dos seus usuários nas diferentes disciplinas e áreas do conhecimento, sobretudo, às ligadas ao campo educacional.

O curso superior para formação de professores de Língua Brasileira de Sinais que a legislação exige e menciona é atualmente ofertado, além de outras instituições, pela Universidade Federal de Santa Catarina (UFSC). O Curso de Letras - Libras foi promovido e oferecido por essa instituição inicialmente em 2006 na modalidade à distância (QUADROS \& STUMPF, 2009) e hoje também vem sendo oferecido regularmente na modalidade presencial. Os alunos que se formam nesse curso recebem a titulação de licenciados em Língua Brasileira de Sinais, tornando-se competentes para atuação como professores de Libras em esfera educacional. Outra possibilidade de habilitação é a titulação de bacharelado cuja formação capacita profissionais tradutores e intérpretes da língua e/ou pesquisadores.

O ano de 1880 foi marcante na história dos Surdos. Nas palavras de Strobel:

Realizou-se o Congresso Internacional de Surdo-Mudez, em Milão Itália, onde o método oral foi votado o mais adequado a ser adotado pelas escolas de surdos e a língua de sinais foi proibida oficialmente alegando que a mesma destruía a capacidade da fala dos surdos, argumentando que os surdos são "preguiçosos" para falar, preferindo a usar a língua de sinais. Alexander Graham Bell teve grande influência 
neste congresso. Este congresso foi organizado, patrocinado e conduzido por muitos especialistas ouvintes na área de surdez, todos defensores do oralismo puro (a maioria já havia empenhado muito antes do congresso em fazer prevalecer o método oral puro no ensino dos surdos). $\mathrm{Na}$ ocasião de votação na assembleia geral realizada no congresso todos os professores surdos foram negados o direito de votar e excluídos, dos 164 representantes presentes ouvintes, apenas 5 dos Estados Unidos votaram contra o oralismo puro (STROBEL, 2008, p. 26).

Essa decisão, em 1880, afetou toda a comunidade Surda em vários países durante muitos anos. Porém, segundo Quadros (2007):

As línguas de sinais de vários países foram preservadas e passadas de geração em geração por meio das associações de surdos e famílias de surdos. No Brasil, as associações de surdos sempre mantiveram intercâmbios por meio de redes possibilitando contatos entre surdos do país inteiro. As festas, os jogos, os campeonatos, as sedes organizadas por surdos são formas de interação social e linguística que não aparecem nas escolas de surdos (muito menos nas escolas regulares) por representarem movimentos de resistência a um sistema que poda, que determina, que lesa a formação da comunidade surda brasileira (QUADROS, 2007, p. 2).

Felizmente, nos últimos anos a situação vem mudando significativamente para melhor, mesmo que os surdos continuem enfrentando diferentes tipos de limitações decorrentes das políticas linguísticas ainda vigentes no país, uma vez que para Quadros: “A política linguística brasileira ainda é pautada na crença de que o país seja monolíngue, favorecendo a língua portuguesa em detrimento das tantas outras línguas existentes no nosso país” (2005 apud QUADROS, 2007, p. 1). De acordo com Quadros:

As políticas linguísticas ainda acreditam no caráter instrumental da língua de sinais brasileira na educação de surdos. As línguas que fazem parte da vida dos Surdos na sociedade apresentam papéis e representações diferenciadas caracterizando uma forma bilíngue de ser (QUADROS, 2007, p. 8).

Posto isso, vale considerar que as comunidades Surdas ainda estão construindo suas políticas linguísticas com objetivos de preservar sua história, sua cultura e os direitos humanos, produzindo pesquisas diretamente em Libras, bem como respeitar e valorizar a língua de sinais usada por essas comunidades. 


\section{Breve metodologia de pesquisa}

O presente artigo coleta algumas propostas que são consideradas como sustentadoras das políticas linguísticas das comunidades acadêmicas surdas ${ }^{4}$, disponibilizadas na internet e controladas pelas instituições de ensino superior conhecidas pela comunidade surda brasileira, explorando as discussões e reflexões fundamentadas sobre as propostas coletadas.

\section{Difusão da Libras: redes de internet, tecnologias e suas interfaces}

Para compreender os novos espaços que a Libras abrange atualmente, vale pontuar as redes de internet, as novas tecnologias e suas interfaces como meios de difusão e fortalecimento linguístico. Inúmeros exemplos poderiam ser citados nesse contexto. Um em especial, que compartilha o caráter acadêmico, pode ser pontuado. É o caso do Portal Libras $^{5}$ desenvolvido pela Universidade Federal de Santa Catarina. O portal tem como objetivo disponibilizar todas as páginas da UFSC que envolvam materiais, textos acadêmicos e atividades envolvendo a Libras em um único sítio eletrônico, a fim de socializar e facilitar o acesso às informações relativas a esta língua. $\mathrm{Na}$ imagem abaixo é possível ver uma fotografia que ilustra a página do portal com uma apresentadora, surda, que contextualiza em Libras as informações que o usuário poderá acessar.

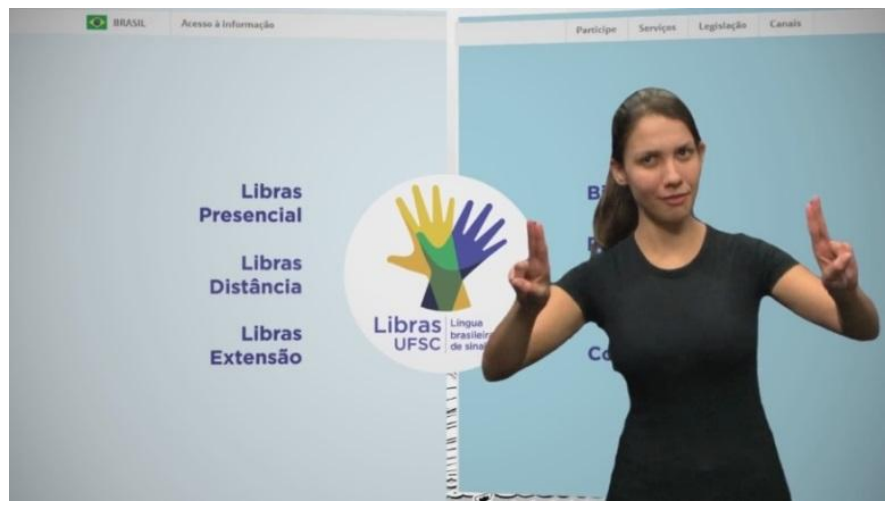

Figura 1: página do Portal Libras com a apresentadora em Libras.

Esse portal disponibiliza todos os materiais, produções, informações e documentos relativos à Libras da UFSC. Alguns dos links que podem ser acessados são: informações

\footnotetext{
${ }^{4}$ Usa-se o termo "algumas" por haver condições limitadas para buscar e analisar as propostas possíveis.

${ }^{5}$ Acesso disponível em: < http://libras.ufsc.br/>.
} 
sobre o curso de Letras - Libras presencial, informações sobre o curso de Letras - Libras à distância, cursos e projetos de extensão relacionados à língua, biblioteca com inúmeras produções acadêmicas em Libras, glossários e vários outros projetos desenvolvidos.

Observa-se que os linkes "biblioteca" e "glossários", que disponibilizam materiais didáticos, produções acadêmicas, publicações, etc., são os mais acessados. Todos esses materiais são importantes ferramentas de formação de professores, pesquisadores e profissionais que atuam na área. A disponibilidade desses materiais na rede, gratuitamente, contribui não só com a formação dos usuários e consumidores dessas produções, mas também com o fortalecimento da área, em paralelo, com as políticas relacionadas. O portal, portanto, é uma forma concreta de valorização da Libras por meio da socialização de produções acadêmicas em diferentes níveis: ensino, pesquisa e extensão.

Outra proposta interessante é a que o Instituto Nacional de Educação de Surdos (INES) disponibiliza na página do grupo de pesquisa: Manuário Acadêmico e Escolar ${ }^{6}$.

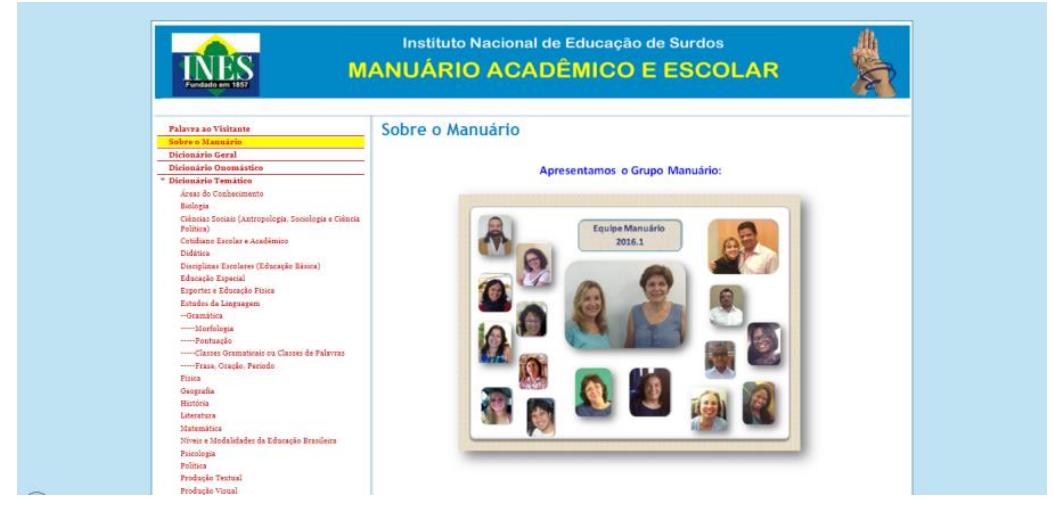

Figura 2: página do Manuário Acadêmico e Escolar do INES.

Observa-se que a página do projeto Manuário Acadêmico e Escolar tem algumas das ferramentas em destaque, por exemplo, disponibiliza o Dicionário Onomástico ${ }^{7}$ e também os sinais técnicos para a área acadêmica, da mesma forma que o glossário do Portal Libras é destacado para a área linguística e de Letras - Libras.

Há também outras inúmeras iniciativas no país envolvendo ferramentas disponibilizadas na internet que poderiam ser citadas. Outras duas que valem ser pontuadas pelo crescente uso e abrangência são os aplicativos (de tradução automática) conhecidos

\footnotetext{
${ }^{6}$ Acesso disponível em: <http://www.manuario.com.br/>.

7 Esse dicionário disponibiliza os sinais para vários autores mais importantes (por exemplo: Bakhtin, Chomsky, Foucault, Paulo Freire, Freud, Saussure, Stokoe, Piaget, Vygostsky, entre outros).
} 
como HandTalk e ProDeaf. São ferramentas para dispositivos móveis de novas tecnologias que possibilitam traduzir o texto automaticamente da língua portuguesa para a Libras e ajudam tanto os usuários das línguas quanto os iniciantes e aprendizes das duas línguas. As plataformas de compartilhamento e carregamento de vídeos também podem ser aqui lembradas, como é o caso do YouTube e as novas redes sociais, tal qual o Facebook. Sem dúvida, são ferramentas significativamente usadas pelas comunidades surdas devido às infinitas possibilidades de disponibilizar, compartilhar e consumir vídeos com produções registradas em Libras e outras línguas de sinais.

Vale destacar que o vídeo-registro se trata de um recurso audiovisual amplamente empregado hoje em dia pelos usuários da Libras das comunidades surdas enquanto ferramenta de registro da língua. O vídeo, atualmente, possibilita e facilita a comunicação entre os usuários desta língua e, consequentemente, enquanto nova ferramenta tecnológica acessível e de fácil uso, também desempenha um importante papel na consolidação da língua e das políticas linguísticas dos surdos no país.

A Língua Brasileira de Sinais e as demais línguas de sinais de forma geral se caracterizam pela sua modalidade espaço-visual, desta forma, "a informação linguística é recebida pelos olhos e produzida pelas mãos” (QUADROS \& KARNOPP, 2004, p. 47-48). O vídeo, portanto, pode ser considerado um recurso eficaz para registrar, apresentar e difundir a língua de sinais.

Além de oportunizar o compartilhamento desses vídeos que registram e carregam conteúdos, textos, discursos e os "dizeres surdos", essas novas ferramentas e espaços de relacionamento e interação possibilitam também uma importante troca entre os usuários surdos de todo o país e mundo, favorecendo o encontro surdo-surdo (mesmo que virtualmente), o que viabiliza articulações políticas importantes para o reconhecimento e valorização da língua e das comunidades.

\section{Uma proposta merece ser explorada: Libras no campo acadêmico, normas e produções}

De acordo com MEC/Relatório (2014), a compreensão dos direitos de uma pessoa usuária de outra língua que não a oficial no país em que vive, expressa na $24^{a}$ Declaração 
Universal dos Direitos Linguísticos, se mantém na Convenção sobre Direitos das Pessoas com Deficiência, em relação aos Surdos, no artigo 24 do documento:

a) Facilitação do aprendizado da língua de sinais e promoção da identidade linguística das comunidades Surdas;

b) Garantia de que a educação de pessoas cegas, surdocegas e surdas seja ministrada nas línguas e nos modos e meios de comunicação mais adequados a essas pessoas e em ambientes que favoreçam ao máximo seu desenvolvimento acadêmico e social.

A partir da Lei $n^{\circ} 10.436 / 2002^{8}$ e do Decreto n $5.626 / 2005^{9}$ os direitos linguísticos dos surdos brasileiros passaram a ser reconhecidos e valorizados, sobretudo na área de educação e nas políticas de acesso à comunicação e ao conhecimento. Outra lei que vale destacar, importante atualmente para a consolidação das novas políticas linguísticas das comunidades surdas, publicada em 2015, é a Lei Brasileira de Inclusão, no $13.146^{10}$, que incentiva a produção de artigos científicos acessíveis, incluindo o uso da Libras em sua construção e publicação. De acordo com o artigo $68, \mathbb{\int} 3^{\circ}$ da Lei: “O poder público deve estimular e apoiar a adaptação e a produção de artigos científicos em formato acessível, inclusive em Libras". Esse fato é um passo fundamental nas políticas linguísticas da Libras no Brasil. Diante da legislação que apresenta uma política linguística favorável à língua de sinais, várias ações estão sendo desencadeadas em relação à esta língua.

Silva (2013) apresenta um exemplo comparativo pertinente que pode influenciar no desenvolvimento e na difusão dos tipos de registro da Libras, no caso do registro formal. Sabe-se que, em grande parte, as universidades brasileiras costumam adotar as recomendações da Associação Brasileira de Normas Técnicas (ABNT) para a normatização de textos acadêmicos e científicos registrados na língua portuguesa escrita. Entende-se que essa normatização fortalece a formalidade acadêmica necessária e o padrão técnico no desenvolvimento das produções científicas. Já no caso da Libras essa normatização pode ser aplicada no seu registro em vídeo e entendida como uma proposta de orientação técnica nas produções acadêmicas e científicas desenvolvidas em língua de sinais.

Na Universidade Federal de Santa Catarina (UFSC), existe atualmente um grupo de

\footnotetext{
${ }^{8}$ Dispõe sobre a Língua Brasileira de Sinais - Libras e dá outras providências.

${ }^{9}$ Regulamenta a Lei $\mathrm{n}^{\circ}$ 10.436, de 24 de abril de 2002, que dispõe sobre a Língua Brasileira de Sinais - Libras, e o art. 18 da Lei n 10.098 , de 19 de dezembro de 2000.

${ }^{10}$ Institui a Lei Brasileira de Inclusão da Pessoa com Deficiência (Estatuto da Pessoa com Deficiência).
} 
pesquisa que realiza discussões, investigações e propostas sobre modelos e normas técnicas aplicadas à Libras como registro de produções acadêmicas, sob a coordenação do professor Dr. Rodrigo Rosso Marques, junto com os professores Me. Rodrigo Custódio da Silva e Me. Alexandre Bet da Rosa Cardoso ${ }^{11}$. O Grupo de Pesquisa em Video Registro em Libras (VRLibras) iniciou seus trabalhos no ano de 2011 e desde então vem desenvolvendo encontros de discussão e experimentação sobre essas normas. Em 2012 houve a oportunidade de publicar as normas pesquisadas, experimentadas e então definidas no grupo. Essa publicação foi realizada em Libras e pode ser acessada no próprio site do projeto, que também contempla a primeira Revista Brasileira de Vídeo Registro em Libras ${ }^{12}$.

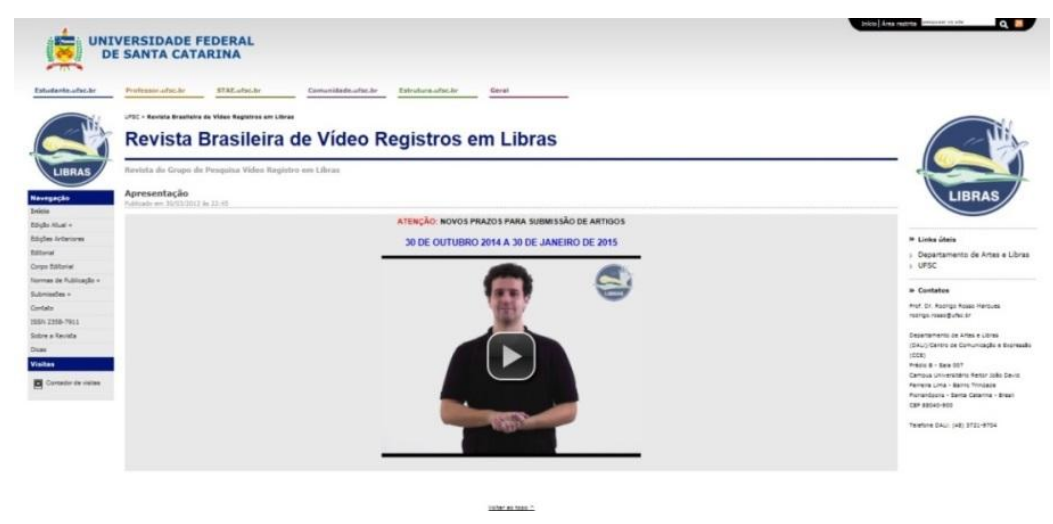

Figura 3: página do Vídeo Registros em Libras.

Para explicitar esse projeto, vale compartilhar as palavras de Marques e Oliveira (2012, p. 1): “os pesquisadores do grupo buscam legitimar essa forma de registro mostrando que é possível padronizar a produção do gênero acadêmico em Libras". Os autores entendem que "há necessidade de sistematização e organização para evitar que ela [a língua] caia no informalismo" (MARQUES \& OLIVEIRA, 2012, p. 6). Em 2013, a revista publicou os primeiros cincos artigos científicos produzidos diretamente na Libras.

${ }^{11}$ Três membros e pesquisadores do grupo são professores da UFSC.

12 Acesso disponível em: <http://revistabrasileiravrlibras.paginas.ufsc.br/>. 


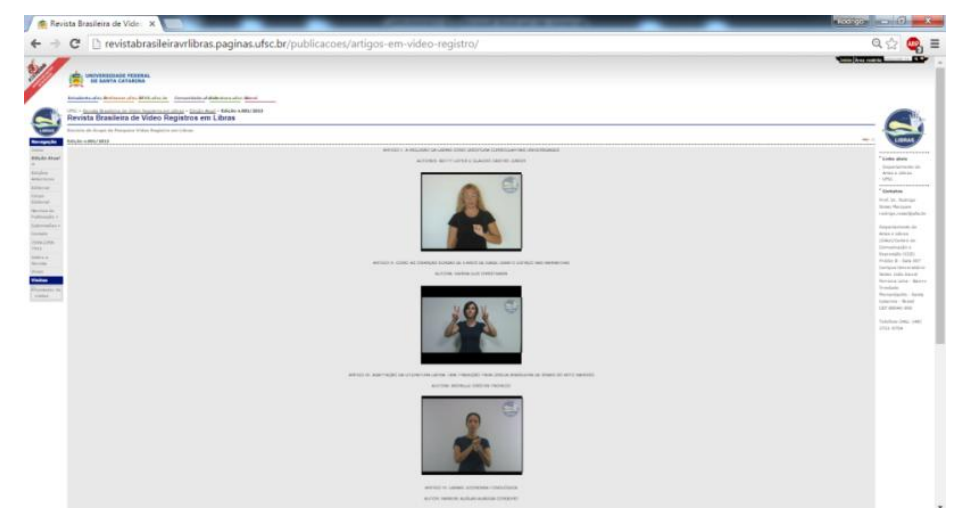

Figura 4: página da $1^{a}$ edição de artigos da revista Vídeo Registros em Libras.

Em 2016, foram publicados mais quatro artigos científicos em Libras na revista Vídeo Registros em Libras. Além da publicação, as normas disponíveis no site da revista são conhecidas e difundidas em diferentes universidades e eventos científicos no Brasil. Atualmente, percebe-se um aumento significativo do número de produções acadêmicas textuais em Libras disponibilizadas, principalmente, na internet. Essas produções podem ser entendidas como produções de gênero acadêmico, um novo modelo comunicacional que a língua de sinais passa a contemplar. Nesse contexto, vale compartilhar as palavras de Marcuschi:

Gênero textual refere os textos materializados em situações comunicativas recorrentes. Os gêneros textuais são os textos que encontramos em nossa vida diária e que apresentam padrões sociocomunicativos característicos definidos por composições funcionais, objetivos enunciativos e estilos concretamente realizados na integração de forças históricas, sociais, institucionais e técnicas (MARCUSCHI, 2008, p. 155).

É crescente o uso da Libras nos diferentes contextos sociais, consequentemente, aumentando o acesso dos surdos na sociedade. A utilização abrangente da língua de sinais vem gradualmente construindo novos espaços: escolares, acadêmicos, empresariais, jurídicos, etc. É natural cada espaço desenvolver um gênero textual de acordo com as características do contexto em que a língua é usada. A construção desses novos gêneros textuais amplia as possibilidades e usos da Libras e, consequentemente, passa a contemplar novas formas de comunicação, novos usuários e novos horizontes.

É importante reconhecer que não há como traçar um comparativo entre a Libras e a língua portuguesa por meio de números e quantificação de produções textuais e de materiais diversos, uma vez que são línguas que possuem constituições históricas 
completamente diferentes, bem como percursos de constituição e consolidação que muito se diferem. Cada língua possui sua história, suas produções, seus tipos de registro e sistemas de escrita e documentação. Cada uma delas é constituída de uma modalidade particular que implica nas suas formas de registro e uso, seu registro formal e/ou informal, sua estrutura sintática, sua semântica, etc.

Uma língua independe da outra. Ao contrário do que muitos ainda acreditam e de acordo com o que muitos autores e pesquisadores vem há anos desmistificando em suas escritas, a Língua Brasileira de Sinais não depende da língua portuguesa; não é de forma alguma uma versão simplificada desta. Neste contexto, vale compartilhar os apontamentos de Silva (2013), que argumenta que:

Não se deve considerar, contudo, que as línguas de sinais precisem necessariamente das línguas faladas para que possam obter seu grau de formalidade. É preciso que as línguas de sinais busquem conhecer e adotar o universo do sistema linguístico, acadêmico, cultural e social para que possam desenvolver o status do seu próprio fenômeno linguístico. (SILVA, 2013, p. 49).

Conforme a pesquisa de Silva (2013), a Libras também se manifesta em seu registro formal. O seu uso está associado ao contexto em que está presente. Sua propriedade de criatividade e versatilidade comprova a possibilidade de emprego infinito da língua e adequação a cada esfera e a cada contexto. Essa capacidade de uso natural e em quaisquer circunstâncias é um meio poderoso de fortalecimento do discurso de seus usuários. Estando seus usuários cada vez mais presentes no contexto acadêmico, sua língua também se fará presente diretamente ou indiretamente e, nesse contexto ela se manifestará e se moldará. A partir do que é produzido e consolidado em determinado contexto de uso da língua é que novas políticas linguísticas irão aparecer, se renovar e transformar.

Quanto maior for o número de produções textuais materializadas e disponibilizadas ao público, mais os usuários da língua terão oportunidade de acessar, perceber e aprender a língua; sua estrutura, as particularidades linguísticas de cada gênero textual, etc. Assim como terão mais acesso à informação e ao conhecimento. Isso contribui com uma circulação da língua significativamente fortalecida, bem como de suas produções a partir dela gerada. 


\section{Considerações finais}

Este trabalho buscou apresentar ao leitor, de forma breve, a existência de algumas propostas que sustentam as políticas linguísticas da Língua Brasileira de Sinais, em especial, as produções acadêmicas em Libras como ferramentas importantes para as comunidades acadêmicas Surdas no Brasil.

Entende-se que a Libras em seu registro formal e acadêmico pode contribuir para o desenvolvimento e constituição de novos gêneros textuais bastante característicos. Esses gêneros textuais podem ser entendidos como modelos comunicativos, bem como considera Marcuschi: "Gêneros não são entidades naturais como as borboletas, as pedras, os rios e as estrelas, mas são artefatos culturais construídos historicamente pelo ser humano" (2010, p. 31). Acrescenta, ainda: “[...] os gêneros são modelos comunicativos. Servem, muitas vezes, para criar uma expectativa no interlocutor e prepará-lo para uma determinada reação" (2010, p. 35).

$\mathrm{Na}$ medida em que as comunidades surdas e os usuários da Língua Brasileira de Sinais no Brasil passam a ter mais oportunidades de estudar, aprender e estar inseridos em novos espaços sociais, bem como se fortalecer nos antigos espaços já conquistados, o emprego da Libras passa a atingir novos níveis e alcançar novos caminhos. A Libras passa a ser usada de formas diversas e seus gêneros textuais passam a ser significativamente ampliados.

Quando os usuários da Libras tiverem novos caminhos oportunizados para acessar novos usos da sua língua, novos gêneros textuais que a sua língua se materializa, suas habilidades e conhecimentos linguísticos avançarão e se desenvolverão, assim como Marcuschi observa: "um maior conhecimento do funcionamento dos gêneros textuais é importante tanto para a produção como para a compreensão" (2010, p. 34).

Nesse sentido vale finalizar lembrando que, para que seja possível avançar nas políticas linguísticas da Libras, é necessário incentivar mais a produção de materiais em Libras, a produção acadêmica, os artigos científicos, os trabalhos em língua de sinais. Ainda, os usuários devem investir na qualidade da própria sinalização, enriquecendo assim as políticas linguísticas e o status linguístico da Libras e das línguas de sinais. Assim será possível obter um maior estímulo para mobilizar todo seu conhecimento prévio para a compreensão e produção textual. 
Este artigo não pode levantar todas as propostas existentes na internet devido às condições limitadas da pesquisa, mas o limite de qualquer pesquisa pode dar oportunidades para outros continuarem a aprofundar o tema no futuro.

\section{Agradecimentos}

À professora Ronice Müller de Quadros, pelas contribuições e orientações neste trabalho, e a Danielle Vanessa Costa de Sousa, pelo diálogo e discussão sobre o tema.

\section{Referências}

BRASIL. Decreto n. 5.626, de 22 de dezembro de 2005. Regulamenta a Lei no 10.436, de 24 de abril de 2002, que dispõe sobre a Língua Brasileira de Sinais - Libras, e o art. 18 da Lei no 10.098, de 19 de dezembro de 2000. Diário Oficial [da] República Federativa do Brasil, Brasília, DF, 23 dez. 2005.

Lei n. 10.436, de 24 de abril de 2002. Dispõe sobre a Língua Brasileira de Sinais Libras e dá outras providências. Diário Oficial [da] República Federativa do Brasil, Brasília, DF, 25 abr. 2002.

Lei n. 13.146, de 6 de julho de 2015. Institui a Lei Brasileira de Inclusão da Pessoa com Deficiência (Estatuto da Pessoa com Deficiência). Disponível em: $<$ http://www.planalto.gov.br/ccivil 03/Ato2015-2018/2015/Lei/L13146.htm>. Acesso em: 26 de Abr. 2018.

CAMPELLO, Ana Regina e Souza. A constituição histórica da Língua de Sinais Brasileira: século XVIII a XXI. Revista Mundo \& Letras, v. 2. José Bonifácio/SP, Jul. 2011.

DINIZ, Heloise Gripp. A história da língua de sinais brasileira (Libras): um estudo descritivo de mudanças fonológicas e lexicais. Dissertação (Mestrado em Linguística). Florianópolis: Universidade Federal de Santa Catarina, 2010.

FERREIRA, Lucinda. Por uma gramática de línguas de sinais. Rio de Janeiro: Tempo Brasileiro, 2010.

GESSER, Audrei. LIBRAS? Que língua é essa?: crenças e preconceitos em torno da língua de sinais e da realidade surda. São Paulo: Parábola Editorial, 2009.

MACHADO, Anna Rachel; LOUSADA, Eliane; ABREU-TARDELLI, Lília Santos. Planejar gêneros acadêmicos: escrita científica - texto acadêmico - diário de pesquisa metodologia. São Paulo: Parábola Editorial, 2005.

MARCUSCHI, Luiz Antônio. Produção textual, análise de gêneros e compreensão. 
São Paulo: Parábola Editorial, 2008.

MARCUSCHI, Luiz Antônio. Gêneros textuais: definição e funcionalidade. In: DIONISIO, Angela Paiva; MACHADO, Anna Rachel; BEZERRA, Maria Auxiliadora. (Org.). Gêneros textuais e ensino. São Paulo: Parábola Editorial, 2010.

MARQUES, Rodrigo Rosso; OLIVEIRA, Janine Soares de. A normatização de artigos acadêmicos em Libras e sua relevância como instrumento de constituição de corpus de referência para tradutores. In: QUADROS, Ronice Muller de (Org.). Anais do III Congresso Nacional de Pesquisas em Tradução e Interpretação de Libras e Língua Portuguesa. Florianópolis: 2012.

MEC/SECADI. Relatório sobre a Política Linguística de Educação Bilíngue Língua Brasileira de Sinais e Língua Portuguesa, no 1.060/2013 e nº 91/2013. Brasília, DF, 2014. Disponível em: $<$ www.bibliotecadigital.unicamp.br/document/?down=56513 > . Acesso em: 25 de Fev. 2015.

QUADROS, Ronice Muller. de. Políticas lingüísticas e educação de surdos. Anais do Congresso: Surdez, família, linguagem e educação. Rio de Janeiro: INES, 2007, v.1, p. 94-102.

; KARNOPP, L. B. Língua de Sinais Brasileira: estudos lingüísticos. Porto Alegre: Artes Médicas, 2004.

; STUMPF, Marianne Rossi. O primeiro curso de graduação em Letras língua brasileira de sinais: educação à distância. ETD - Educação Temática Digital, v. 10, n. 2, Jun. 2009, p. 169-185.

SILVA, Rodrigo Custódio da. Indicadores de formalidade no gênero monológico em Libras. Dissertação (Mestrado em Linguística). Florianópolis: Universidade Federal de Santa Catarina, 2013.

STROBEL, Karin. Texto-base da disciplina de História da Educação de Surdos. Curso de Letras-Libras - EaD. Florianópolis: UFSC, 2009. (Material didático para História da Educação de Surdos). Disponível em:

<http://www.libras.ufsc.br/colecaoLetrasLibras/eixoFormacaoEspecifica/historiaDaEdu cacaoDeSurdos/assets/258/TextoBase HistoriaEducacaoSurdos.pdf > . Acesso em: 26 de Abr. 2018. 


\section{Abstract}

This work presents proposals for academic productions in the Brazilian Sign Language (Libras) as tools of linguistic policy of the Brazilian academic community Deaf. To contextualize the theme, some considerations about the history of sign language in Brazil are presented, as well as reflections on its diffusion, the use of new communication networks and the educational and academic contexts of use of Libras. Theoretical and legal references about the sign language at the academic interface and their respective formal registration are brought to bear on this work. The closing of this article is given with the indication of the importance of investing in the viability and production of materials that covers new genres of use and registration of sign language in Brazil, since they are important in the path of solidification of the language and community of linguistic policy.

Keywords: Libras. Academic productions. Linguistic policies 